\title{
Should Codeine Still Be Considered a WHO Essential Medicine?
}

\author{
Bonifasius S. Singu and Roger K. Verbeeck \\ School of Pharmacy, Faculty of Health Sciences, University of Namibia, Windhoek, Namibia
}

Corresponding author: Bonifasius S. Singu, School of Pharmacy, Faculty of Health Sciences, University of Namibia, Private Bag 13301 Windhoek, Namibia; email: bsingu@unam.na

Received, May 30, 2021; Accepted, June 25, 2021; Published, June 26, 2021

\begin{abstract}
Codeine continues to be widely used as an analgesic, antidiarrhoeal and antitussive agent. Its analgesic effect depends on its biotransformation to morphine, a strong opioid. The highly variable biotransformation of codeine to morphine, catalysed by CYP2D6, underlies the pronounced interindividual variability of its analgesic response. Randomized controlled trials have demonstrated that codeine administered alone has the poorest analgesic effect among all commonly used analgesics in acute postoperative pain. Moreover, it is highly unlikely that the low dose of codeine contributes to the pain-relieving effect of the nonopioid component in combination analgesic products. In addition, there is a lack of reliable clinical evidence to support the use of codeine as an antitussive in acute or chronic cough. Codeine use, through its active metabolite morphine, has the potential to lead to abuse and dependence. The World Health Organization (WHO) removed codeine from the essential medicines list for children in 2011. Based on the available information in the scientific literature on the efficacy and safety of codeine, the WHO should seriously consider removing it also from the list of essential medicines for adults, which would be a strong signal for all health professionals to prescribe and dispense codeine with the utmost caution.
\end{abstract}

\section{INTRODUCTION}

Codeine (3-methyl-morphine) is an alkaloid first isolated from the dried latex of the seed capsules of the opium poppy, Papaver somniferum [1]. Although, strictly speaking, codeine (as well as morphine) is an opiate because it is derived from the resin of the opium poppy, in this review the term opioid will be generally used for all agents that have the functional and pharmacological properties of an opiate. Codeine is one of the most widely available and consumed opioids worldwide, and is most commonly used for its analgesic, antitussive and anti-diarrhoeal properties [1,2]. Although generally viewed as a "weak" opioid, it has the potential for abuse leading to physical and psychological dependence. In addition, high pharmacogenetic variability in the metabolism of codeine seriously complicates its effective and safe use [3]. Here, various arguments will be presented why codeine should no longer be maintained on the WHO (World Health Organization) List of Essential Medicines [4].

\section{THE BIOACTIVATION OF CODEINE TO MORPHINE IS HIGHLY VARIABLE}

Codeine is a prodrug that only weakly binds to the $\mu$-opioid receptor (Table 1). Its analgesic properties are generally believed to result from the conversion to morphine, a strong opioid agonist, that binds to the $\mu$-opioid receptor with a 200-fold greater affinity than codeine $[5,6]$. Codeine is eliminated by metabolism (Fig. 1) [3,7]. The main elimination pathway (approximately 80\%) is glucuronidation to codeine-6-glucuronide. A highly variable amount of codeine, approximately 0 to $10 \%$, is biotransformed to morphine, which is further metabolised to morphine-3-glucuronide, morphine-6-glucuronide, and normorphine [3,5]. Codeine-6-glucuronide has been shown to have low affinity for the $\mu$-opioid receptors and analgesic activity in rats similar to that of codeine $[5,6,8,9]$. Codeine is also metabolised by an unknown mechanism to hydrocodone, an opioid with antinociceptive and euphoric properties similar to those of morphine, but the quantities recovered in urine are very small $(<0.5 \%$ of the administered codeine dose) [10]. Morphine-6glucuronide is a strong opioid agonist with higher affinity for the $\mu$-opioid receptor than morphine itself, and together with morphine contributes to the analgesic activity following codeine administration [11]. Consequently, classifying codeine as a "weak" opioid is misleading because the analgesic activity following its administration is largely, if not entirely, mediated by its metabolites, morphine and morphine-6glucuronide, which are strong opioids [3,7].

The highly polymorphic cytochrome P450 
isoenzyme CYP2D6 is responsible for the metabolism of codeine to its active metabolite morphine [3]. The activity of CYP2D6 is under genetic control and individuals can be categorized as poor, intermediate, extensive, or ultra-rapid metabolizers [3]. CYP2D6 allele frequencies vary considerably across ethnic groups. The prevalence of the ultra-rapid metabolizer varies widely and has been estimated at 0.5 to $1 \%$ in Chinese and Japanese, 1 to $10 \%$ in Caucasians, $3 \%$ in African Americans, and 16 to $30 \%$ in North Africans, Ethiopians, and Arabs [3,12]. Patients who are CYP2D6 poor metabolizers will have no analgesic effect after codeine administration but may suffer adverse effects from codeine [13]. In contrast, ultra-rapid metabolizers are able to metabolize a higher fraction of the codeine dose to morphine, and even at normal codeine doses, these patients may experience the symptoms of morphine overdose, which include extreme sleepiness, confusion, and shallow breathing due to CNS depression [3]. Consequently, the use of codeine should be avoided in poor metabolizers due to the lack of efficacy, and in ultra-rapid metabolizers due to the high risk of serious toxicity. In practice, this means that without prior genotyping/phenotyping of the patient the safe and effective use of codeine is not possible [3]. The genotype of the patient, the renal function, and drug interactions have been shown to be significantly associated with codeine related hospitalizations and death $[14,15]$.

\section{PHARMACOTHERAPEUTIC VALUE OF CODEINE}

\section{Codeine has poor and unpredictable analgesic efficacy}

An overview of 39 separate Cochrane reviews on 54 different oral analgesic products, including single analgesic component products at different dose strengths, as well as fixed dose combinations of commonly used analgesics, showed that codeine $60 \mathrm{mg}$ is by far the least effective analgesic to treat moderate to acute post-operative pain in adults [16]. For the 54 different oral analgesic products that were tested using a randomised, double-blind, placebo-controlled trial, the number of patients needed to treat (NNT) to have one patient with at least $50 \%$ pain relief over 4 to 6 hours, varied from 1.5 to 12 . Seventy eight percent of the analgesic products (i.e., 42 of the 54 products) had an NNT of less than 4; codeine $(60 \mathrm{mg})$ had an NNT of 12. Very likely, the approximately $10 \%$ of patients in whom a $60 \mathrm{mg}$ dose of codeine reduces the pain by $50 \%$, are those who transform a sufficient fraction of the codeine dose into morphine.
Table 1. Inhibition constants $\left(K_{i}\right)$ of codeine and its main metabolites for the binding of the highly specific $\mu$-opioid receptor ligand ${ }^{3} \mathrm{H}$-DAMGO [4]. The lower the $\mathrm{K}_{\mathrm{i}}$, the higher the affinity for the $\mu$-opioid receptor.

\begin{tabular}{l|l}
\hline Substance & $\mathrm{K}_{\mathrm{i}}(\mathrm{nM})$ \\
\hline norcodeine & 367 \\
codeine & $\mathbf{2 4 8}$ \\
codeine-6-glucuronide & 239 \\
morphine-3-glucuronide & 37 \\
hydrocodone & 20 \\
morphine & 1.2 \\
morphine-6-glucuronide & 0.6 \\
\hline
\end{tabular}

A Cochrane review on the efficacy of a single oral administration of paracetamol plus codeine in acute post-operative pain in adults was carried out including data from 26 studies on a total of 2295 participants [17]. A significant analgesic response vs. dose was observed with NNTs of 2.2 for 800 to $1000 \mathrm{mg}$ paracetamol plus $60 \mathrm{mg}$ codeine, 3.9 for 600 to $650 \mathrm{mg}$ paracetamol plus $60 \mathrm{mg}$ codeine, and 6.9 for $300 \mathrm{mg}$ paracetamol plus $30 \mathrm{mg}$ codeine. Interestingly, in 14 of the studies (926 participants) paracetamol plus codeine was compared to the same dose of paracetamol alone; addition of codeine increased the proportion of participants achieving at least $50 \%$ pain relief by only 10 to $15 \%$. In three studies (204 participants) of another Cochrane review assessing the analgesic efficacy of the combination of ibuprofen $400 \mathrm{mg}$ plus codeine ( $25.6 \mathrm{mg}$ to $60 \mathrm{mg}$ ), $69 \%$ and $55 \%$ of the participants had at least $50 \%$ maximum pain relief with ibuprofen plus codeine (any dose) or the same dose of ibuprofen alone, respectively, but the result was barely significant [18].

Numerous combination analgesic products containing a low dose of codeine (less than $30 \mathrm{mg}$ codeine phosphate) are marketed and are still available over the counter (OTC) in certain countries. Most of these products contain 8 to 15 $\mathrm{mg}$ codeine phosphate and no reliable clinical studies can be found in the literature demonstrating the contribution of codeine to the analgesic efficacy of these OTC combination products. Since all patients, with the exception of CYP2D6 ultrarapid metabolizers, will convert less than $10 \%$ of the oral codeine dose into morphine, less than $1.1 \mathrm{mg}$ morphine will be formed in vivo after oral administration of $15 \mathrm{mg}$ codeine phosphate [15]. For example, the mean intravenous dose of morphine for post-surgical pain relief has been 


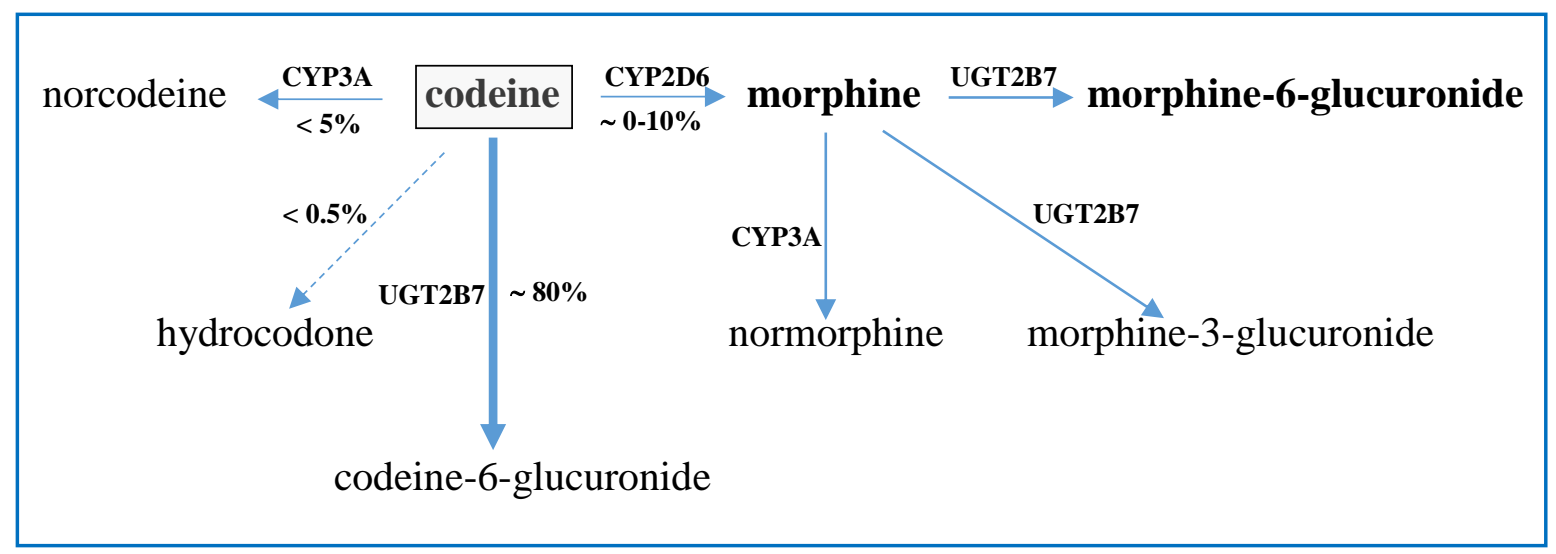

Figure 1. Simplified codeine metabolic scheme. UGT2B7, UDP-glucuronosyltransferase 2B7; CYP3A, cytochrome P450 3A subfamily; CYP2D6, cytochrome P-450 2D6 isoenzyme. Percentages shown indicate the approximate conversion to a particular metabolite.

shown to be approximately $10 \mathrm{mg}$ [19]. It is, therefore, unlikely that the codeine component, via its biotransformation to morphine, will contribute to the analgesic effect of OTC combination analgesic products even in moderate pain, not only in CYP 2D6 poor and intermediate metabolizers but also in CYP2D6 rapid metabolizers [3]. This is supported by a recent systematic review and metaanalysis on the efficacy and safety of low-dose codeine combination analgesic products [20].

Several studies have implicated opioids, including codeine, in the development of medication overuse headache, an often unrecognised condition which affects $1-2 \%$ of the global population [21,22]. Even though opioids are generally not recommended for headache treatment because of their limited potential for pain relief from headache and their abuse potential, in practice they are still regularly used [23]. Several studies have also shown that patients often self-medicate to treat headaches, in some cases with OTC preparations containing a low dose of codeine, or by self-administering opioids prescribed for other pain conditions they are suffering from.

\section{Poor clinical evidence for the antitussive efficacy of codeine}

Despite the widespread use of oral codeine as antitussive medication, there is very little clinical evidence supporting its antitussive activity both in children and adults [24-26]. The lack of sufficient evidence to support the use of codeine has been consistently reaffirmed by medical experts in international chronic cough guidelines and by governing medical and pharmaceutical authorities in countries/regions like the USA, Europe, Canada,
New Zealand, and Australia. Due to the lack of sufficient evidence to support efficacy, and the known risks associated with its use, in particular the increased risks for children, codeine is contraindicated in children less than 12 years of age, and not recommended in adolescents (12 to 18 years) with respiratory conditions.

\section{Codeine as an anti-diarrhoeal agent}

Opioids continue to be widely used in the treatment of diarrhoea [27]. They act locally in the gastrointestinal tract by disrupting neurotransmission between enteric neurons and their effector targets, i.e., smooth muscle cells and epithelial cells, mediated principally through either $\mu$ - or $\delta$-opioid receptors on enteric neurons [28]. Loperamide, which shows minimal penetration into the CNS, is generally recommended over other opioids, such as diphenoxylate and codeine, which readily cross the blood-brain barrier and are, therefore, more liable to generate adverse central effects and cause physical dependency and drug abuse. If codeine is used to treat diarrhoea, the recommended dose is $15-60 \mathrm{mg}$ three to four times daily. Low-dose OTC combination analgesic products should not be used to treat diarrhoea, due to the risk of toxicity of the non-opioid analgesic, e.g., paracetamol or ibuprofen.

\section{CODEINE ABUSE AND ADDICTION}

Codeine abuse and dependence are well documented in the scientific literature [29]. Although the prevalence of codeine misuse/abuse is largely unknown, the resultant effects, including serious morbidity causing great cost to the health care system, are well established [30]. One of the 
principal factors considered to contribute to problematic codeine use is its availability in several countries without a medical prescription. The availability of codeine containing OTC products is associated with public lack of awareness of its misuse/abuse potential and associated health problems. Surveys of pharmacy staff's (registered pharmacists and pharmacy assistants) perspectives on the issue of codeine misuse/abuse in several countries (Australia, Ireland, South Africa, UK) have shown that most participants expressed the view that codeine misuse/abuse is a significant health problem [31,32]. A survey among community pharmacists in Scotland showed that codeine containing products were the most frequently abused form of OTC medication [33]. An exploratory cross-sectional survey among pharmacy customers revealed that $6 \%$ in Ireland, $13 \%$ in South Africa and 16\% in England purchased codeine-containing OTC products on a weekly basis [34]. In addition, misuse/abuse of OTC codeine analgesic combinations has been shown to result in concomitant, serious overconsumption of the non-opioid analgesic component [29]. Promotion of the safe use of codeine and management of its misuse is a public health issue as reports of dependence are on the increase [35].

\section{THE WHO ANALGESIC LADDER}

The WHO guidelines for the pharmacological management of cancer pain are based on a sequential approach, the so-called three-step analgesic ladder, according to intensity of the pain: starting with non-opioid analgesics for the treatment of mild pain (step I), and moving via weak opioids such as codeine in mild-moderate pain (step II) to strong opioids in moderate-severe (step III) [36,37]. However, the usefulness of socalled weak opioids like codeine and tramadol (step II) has been recently questioned [38-41]. Bandieri et al. showed that cancer patients with moderate pain, titrated with normal-release oral morphine up to $30 \mathrm{mg}$ daily followed by slowrelease morphine, experienced an earlier and more adequate level of pain relief compared with patients treated with step II weak opioids, i.e., codeine/paracetamol tablets $(30 \mathrm{mg} / 500 \mathrm{mg})$, tramadol/paracetamol $(37.5 \mathrm{mg} / 375 \mathrm{mg})$, or tramadol alone [41]. Eighty-one percent of the patients treated with weak opioids in this study were receiving up to $180 \mathrm{mg}$ codeine and $4 \mathrm{~g}$ paracetamol daily ( $3 \mathrm{~g}$ from the fixed dose codeine/paracetamol combination plus $1 \mathrm{~g}$ rescue). The European Association for Palliative Care recommends a two-step analgesic approach as an alternative to the WHO three-step analgesic ladder [42]. Since the analgesic effect of codeine is the result of its (highly variable) biotransformation into morphine, it would indeed be rational to replace it by a low dose of morphine, whose pharmacokinetics and pharmacodynamics are far more predictable than those of codeine.

\section{CONCLUSIONS}

Serious concerns over the safe and effective use of codeine for pain relief in children have been expressed for a number of years, and in 2011 the WHO removed codeine from its list of essential medicines for children [43-45]. Codeine has been shown to lead to severe respiratory depression especially in children and adolescents following adenotonsillectomy and as a result its use is now contra-indicated in children under 12 years $[46,47]$. Although codeine use is no longer recommended in breastfeeding women due to potentially serious CNS depression in the breastfed infant, there is little convincing evidence of neonatal toxicity of codeine and other opioids during breastfeeding $[48,49]$.

The false perception, by health professionals and patients alike, that codeine is a "weak" opioid and, therefore, safer than strong opioids such as morphine and fentanyl, is undoubtedly contributing to the continuing increase of its use [2]. Codeine is not a "weak" opioid; it is a prodrug of the strong opioids, morphine and morphine-6glucuronide. The highly variable and unpredictable biotransformation of codeine into morphine represents an additional challenge, and therefore, administering codeine is like administering a highly unpredictable dose of a strong opioid. Most experts agree that without prior genotyping/phenotyping of the patient it is not possible to determine the efficacious and safe analgesic dose of codeine. In case a strong opioid would be the first choice to treat the patient's pain, why not simply use morphine, or another strong opioid, instead of codeine? In addition, it is also fair to say that codeine is not an essential drug for the treatment of diarrhoea (because of its abuse potential), nor for the treatment of acute or chronic cough (where it is basically ineffective).

In some countries, low-dose codeine combination analgesic products are still available without prescription. There are no scientifically based arguments to keep low dose codeine combination analgesic products on the market. They are not effective in most patients but may represent a serious toxicity risk when misused or 
abused. Moreover, applying the principles of evidence-based medicine, and carefully weighing the benefits against the drawbacks, there is also no reason to still use codeine as a single analgesic product to treat pain symptoms. Where an opioid analgesic is indicated, codeine can be rationally replaced by morphine. The WHO Model List of Essential Medicines defines an essential medicine as being "the most efficacious, safe and costeffective medicines for priority conditions" [4]. Even though codeine is an affordable medicine, it is far from the most efficacious and safe analgesic available on the market. Based on the available pharmacological and clinical evidence, the WHO should seriously consider removing codeine also from the adult list of essential medicines. This would give a strong signal to all health professionals to only prescribe and deliver codeine with the utmost caution.

\section{REFERENCES}

1. Yaksh TL, Wallace MS. Opioids, analgesia, and pain management. In: Brunton $\mathrm{L}$, Chabner B, Knollmann B, editors. The Pharmacological Basis of Therapeutics, $12^{\text {th }}$ Edition. New York: McGraw-Hill Medical; 2011.

2. Chenaf C, Kaboré J-L, Delorme J, Pereira B, Mulliez A, Zenut M, et al. Prescription opioid analgesic use in France: trends and impact on morbidity-mortality. Eur J Pain. 2019;23(1):124-34.

https://doi:10.1002/ejp.1291.

3. Crews KR, Gaedigk A, Dunnenberger HM, Shen DD, Callaghan JT, Kharash ED, et al. Clinical Pharmacogenetics Implementation Consortium (CPIC) guidelines for codeine therapy in the context of cytochrome P450 $2 D 6$ (CYP2D6) genotype. Clin Pharmacol Ther. 91(2):321-6, 2012. https:// doi:10.1038/clpt.2013.254.

4. World Health Organization Model List of Essential Medicines, $21^{\text {st }}$ List, 2019. World Health Organisation, 2019. https://apps.who.int/iris/bitstream/handle/10 665/325771/WHO-MVP-EMP-IAU-

2019.06-eng.pdf?ua $=1$.

5. Chen ZR, Irvine RJ, Somogyi AA, Bochner F. Mu receptor binding of some commonly used opioids and their metabolites. Life Sci. 1991;48(22):2165-71.

https://doi:10.1016/0024-3205(91)90150-a.

6. Mignat $\mathrm{C}$, Wille $\mathrm{U}$, Ziegler A. Affinity profiles of morphine, codeine, dihydrocodeine and their glucuronides at receptor subtypes. Life Sci. 1995;56(10):793-9.

https://doi:10.1016/0024-3205(95)00010-4.

7. Vree TB, Verwey-Van Wissen CPWGM. Pharmacokinetics and metabolism of codeine in humans. Biopharm Drug Disp. 1992;13(6):445-60.

https://doi:10.1002/bdd.2510130607.

8. Srinivasan V, Wielbo D, Simpkins J, Karlix J, Sloan K, Tebbett I. Analgesic and immunomodulatory effects of codeine and codeine-6-glucuronide. Pharm Res. 1996; 13(2):296-300.

https://doi:10.1023/a:1016059618633.

9. Srinivasan V, Wielbo D, Tebbett IR. Analgesic effects of codeine-6-glucuronide after intravenous administration. Eur J Pain. 1997;1(3):185-90.

https://doi:10.1016/s1090-3801(97)901038.

10. Oyler JM, Cone EJ, Joseph Jr RE, Huestis MA. Identification of hydrocodone in human urine following controlled codeine administration. J Analyt Toxicol. 2000;24(7):530-5.

https://doi:10.1093/jat/24.7.530.

11. Klimas R, Mikus G. Morphine-6glucuronide is responsible for the analgesic effect after morphine administration: a quantitative review of morphine, morphine6-glucuronide, and morphine-3-glucuronide. $\mathrm{Br} \quad \mathrm{J}$ Anaesth. 2014;113(6):935-44. https://doi:10.1093/bja/aeu186.

12. Gaedigk A, Sangkuhl K, Whirl-Carrillo M, Klein T, Leeder JS. Prediction of CYP2D6 phenotype from genotype across world populations. Genet Med. 2017;19(1):69-76. https://doi:10.1038/gim.2016.80.

13. Eckhardt K, Li S, Ammon S, Schänzle G, Mikus G, Eichelbaum M. Same incidence of adverse drug events after codeine administration irrespective of the genetically determined differences in morphine formation. Pain. 1998;76(1-2):27-33. https://doi:10.1016/s0304-3959(98)000219.

14. Lam J, Woodall KL, Solbeck P, Ross CJD, Carleton BC, Hayden MR, et al. Codeinerelated deaths: the role of pharmacogenetics and drug interactions. Forensic Sci Int. 2014;239:50-6.

https://doi:10.1016/j.forsciint.2014.03.018.

15. Gasche Y, Daali Y, Fathi M, Chiappe A, Cottini S, Dayer $\mathrm{P}$, et al. Codeine intoxication associated with ultrarapid CYP2D6 metabolism. $\mathrm{N}$ Engl J Med. 
2004;351(27):2827-31.

https://doi:10.1056/NEJMoa041888.

16. Moore RA, Derry S, Aldington D, Wiffen PJ. Single dose oral analgesics for acute postoperative pain in adults - an overview of Cochrane reviews. Cochrane Database Syst Rev. 2015;2015(9):CD008659. https://doi:10.1002/14651858.CD008659.p ub3.

17. Toms L, Derry S, Moore RA, McQuay HJ. Single dose oral paracetamol (acetaminophen) with codeine for postoperative pain in adults. Cochrane Database Syst Rev. 2009;2009(1):CD001547.

https://doi:10.1002/14651858.CD001547.p ub2.

18. Derry S, Karlin SM, Moore RA. Single dose oral ibuprofen plus codeine for acute postoperative pain in adults. Cochrane Database Syst Rev. 2015;2015(2):CD01017. https://doi:10.1002/14651858.CD010107.p ub3.

19. Aubrun F, Amour J, Rosenthal D, Coriat P, Riou B. Effects of a loading dose of morphine i.v. morphine titration for postoperative pain relief: a randomized, double-blind, placebo-control study. Br J Anaesth. 2007;98(1):124-30. https://doi:10.1093/bja/ael284.

20. Abdel Shaheed C, Maher CG, McLachlan AJ. Efficacy and safety of low-dose codeinecontaining combination analgesics for pain. Clin J Pain. 2019;35(10):836-43. httpa://doi:10.1097/AJP.000000000000074 6.

21. Diener HC, Limmroth V. Medicationoveruse headache: a worldwide problem. Lancet Neurol. 2004;3(8):475-83. https://doi:10.1016/S1474-4422(04)008245.

22. Scher AI, Lipton RB, Stewart WF, Bigal M. Patterns of medication use by chronic and episodic headache sufferers in the general population: results from the frequent headache epidemiology study. Cephalgia. 2010;30(3):321-8.

https://doi: $10.1111 /$ j.1468-

2982.2009.01913.x.

23. Westergaard ML, Hansen EH, Glümer C, Jensen RH. Prescription pain medications and chronic headache in Denmark: implications for preventing medication overuse. Eur J Clin Pharmacol. 2015;71(7):851-60.

https://doi:10.1007/s00228-015-1858-3.
24. Bolser DC, Davenport PW. Codeine and cough: an ineffective gold standard. Curr Opin Allergy Clin Immunol. 2007;7(1):326.

https://doi:10.1097/ACI.0b013e328011514 5.

25. Morice A, Kardos P. Comprehensive evidence-based review on European antitussives. BMJ Open Respir Res. 2016;3(1):e000137. https://doi:10.1136/bmjresp-2016-000137.

26. Smith SM, Schroeder K, Fahey T. Over-thecounter (OTC) medications for acute cough in children and adults in community settings. Cochrane Database Syst Rev. 2014;2014(11):CD001831.https:// doi: 10.1002/14651858.CD001831.pub5.

27. Schiller LR, Pardi DS, Sellin JH. Chronic diarrhea: diagnosis and management. Clin Gastroenterol Hepatol. 2017;15(2):182-193. https://doi:10.1016/j.cgh.2016.07.028.

28. Sharkey KA, Wallace JL. Treatment of disorders of bowel motility and water flux; anti-emetics; agents used in biliary and pancreatic disease. In: Brunton L, Chabner B, Knollmann B, editors. The Pharmacological Basis of Therapeutics, $12^{\text {th }}$ Edition. New York: McGraw-Hill Medical; 2011.

29. Nielsen S, MacDonald T, Johnson JL. Identifying and treating codeine dependence: a systematic review. Med J Aust. 2018;208(10):451-61. https://doi:10.5694/mja17.00749.

30. Cooper RJ. Over-the-counter medicine abuse - a review of the literature. J Subst Use. 2013,18(2):82-107. https://doi:10.3109/14659891.2011.615002.

31. Carney T, Wells W, Parry CDH, McGuinness P, Harris R. A comparative analysis

of pharmacists' perspectives on codeine use and misuse - a three country survey. Subst Abuse Treat Prev Policy. 2018;13(1):12. https://doi:10.1186/s13011-018-0149-2.

32. Foley M, Carney T, Rich E, Dada S, Mburu C, Parry C. A study of medical professionals' perspectives on medicines containing codeine in South Africa. S Afr J Psychiat. 2018;24:1162. https://doi.10.4102/sajpsychiatry.v24.i0.116 2.

33. Wright J, Bond CM, Robertson HD, Maheson C. Changes in over-the-counter drug misuse over 20 years: perceptions from Scottish pharmacists. J Public Health (Oxf). 
2016;38(4):793-9.

https://doi:10.1093/pubmed/fdv169.

34. Wells, J. S., Bergin, M., Van Hout, M.-C., McGuinness, P., De Pleissisc, J., Rich, E., Dada, S., Wells, R., \& Gooney, M. A. (2018). Purchasing Over The Counter (OTC) Medicinal Products Containing Codeine - Easy Access, Advertising, Misuse and Perceptions of Medicinal Risk. Journal of Pharmacy \&Amp; Pharmaceutical Sciences, 21(1), 286-295. https://doi.org/10.18433/jpps30049

35. Norman, I. J., Bergin, M., Parry, C. D., \& Van Hout, M. C. (2016). Best Practices and Innovations for Managing Codeine Misuse and Dependence. Journal of Pharmacy \&Amp; Pharmaceutical Sciences, 19(3), 367-381. https://doi.org/10.18433/J3T89K

36. Schug SA, Zech D, Dörr U. Cancer pain management according to WHO analgesic guidelines. J Pain Symptom Manage. 1990;5(1):27-32. https://doi:10.1016/s08853924(05)80006-5.

37. WHO Guidelines for the Pharmacological and Radiotherapeutic Management of Cancer Pain in Adults and Adolescents. Geneva: World Health Organization; 2018. Licence CC: BY-NC-SA 3.0 IGO.

38. Swarm R, Abernethy AP, Anghelescu DL, Benedetti C, Buga S, Cleland C, et al. Adult Cancer Pain. J Natl Compr Canc Netw. 2013;11(8):991-1022.

https://doi:10.6004/jncen.2013.0119.

39. Ripamonti CI, Santini D, Maranzano E, Berti M, Roila F, ESMO Guidelines Working Group. Management of cancer pain: ESMO clinical practice guidelines. Ann Oncol. 2012;23(Suppl 7):vii39-54. https://doi:10.1093/annonc/mds233.

40. Goodwin PJ, Bruera E, Stockler M. Pain in patients with cancer. J Clin Oncol. 2014;32(16):1637-9.

https://doi:10.1200/JCO.2014.55.3818.

41. Bandieri E, Romero M, Ripamonti CI, Artioli F, Sichetti D, Fanizza C, et al. Randomized trial of low-dose morphine versus weak opioids in moderate cancer pain. J Clin Oncol. 2016;34(5):436-42. https://doi.10.1200/JCO.2015.61.0733.

42. Caraceni A, Hanks G, Kaasa S, Bennett MI, Brunelli C, Cherni N, et al. Use of opioid analgesics in the treatment of cancer pain: evidence-based recommendations from the EAPC. Lancet Oncol. 2012;13(2):e58-68. https://doi:10.1016/S1470-2045(12)700402.
43. Tremlett MR. Wither codeine? Pediat Anesth. 2013;23(8):677-83. https://doi: 10.1111/pan.12190.

44. Benini F, Barbi E. Doing without codeine: why and what are the alternatives? Ital $\mathbf{J}$ Pediat. 2014;40(1):16 doi: 10.1186/18247288-40-16. https://doi:10.1186/1824-728840-16.

45. WHO Technical Report Series 965. The selection and use of essential medicines. World Health Organisation, 2012. https://apps.who.int/iris/bitsream/ handle/10665/44771/WHO_TRS_965_eng. pdf? sequence $=1$.

46. Kelly LE, Rieder M, van den Anker J, Malkin B, Ross C et al. More codeine fatalities after tonsillectomy in North American children. Pediatrics 2012;129(5):e1343-7. https://doi:10.1542/peds.2011-2538.

47. Racoosin JA, Roberson DW, Pacanowski MA. New evidence about an old drug - risk with codeine after adenotonsillectomy. N Engl J Med. 2013; 368(23):2155-7. https://doi:10.1056/NEJMp1302454.

48. Madadi P, Ross CJD, Hayden MR, Carleton BC, Gaedigk A, Leeder JS, et al. Pharmacogenetics of neonatal opioid toxicity following maternal use of codeine during breastfeeding: a case-control study. Clin Pharmacol Ther.2009;85(1):31-5. https://doi:10.1038/clpt.2008.157.

49. Zipursky J, Juurlink DN. The implausibility of neonatal opioid toxicity from breastfeeding. Clin Pharmacol Ther. 2020;10(5): $\quad 964-70 . \quad$ https://doi: $10.1002 /$ cpt. 1882 . 